\title{
Individual Customer Knowledge Exploitation: A Multiple Case Study
}

\author{
T. S. Mittilä \\ Pori Unit \\ Turku School of Economics at the University of Turku \\ Pori, Finland \\ tuula.mittila@utu.fi
}

\begin{abstract}
We scrutinize how the personnel of industrial companies exploit customer knowledge in service innovation and development. The paper puts in evidence of the factors influencing the absorptive capacity of individuals in industrial service firms.
\end{abstract}

Keywords-knowledge management; absorptive capacity; knowledge exploitation; industrial service; service innovation

\section{INTRODUCTION}

Industrial business transactions are characterized by greater functional interdependence between different parts of a business, greater technical product complexity, stronger buyer-seller interdependence through limited sourcing and technical interrelationships, and greater buying process complexity than consumer transactions [1]. Today, organizations aiming at creating and implementing efficient knowledge strategies and knowledge management systems have to focus on its personnel and business partners as users and producers of customer knowledge.

The purpose of the paper is to scrutinize how the personnel of industrial companies exploit customer knowledge in service innovation and development. The short literature review of the paper addresses knowledge management, absorptive capacity and knowledge exploitation and is presented next. The empirical study focuses on customer knowledge exploitation in the development of industrial services that play a strategic role to the customers. First, the methodology of the multiple case study is introduced and after that, the findings of the study are presented. Finally, we discuss the findings and draw conclusions.

\section{KNOWLEDGE MANAGEMENT}

In innovation and renewal, the role of knowledge management (later referred as $\mathrm{KM}$ ) is to facilitate the creation of new ideas via the acquisition of new knowledge and combining existing knowledge in a novel way (by utilizing an organization's knowledge storage, for example). Ref. [2] introduced three major roles of KM in innovation processes. The first driver of KM's role in innovation is to create, build and maintain competitive advantage through the utilization of knowledge (the integration of $\mathrm{KM}$ into the company strategy, for example). The second driver is that knowledge is a resource used to reduce complexity in the innovation process (e.g. knowledge storage and organizational memory). The third driver of applying KM for the benefit of the innovation process is the integration of knowledge in the organization and making it more available and accessible (e.g. knowledge management systems).

A knowledge life cycle process is divided into three sequential steps: knowledge production, knowledge validation, and knowledge integration [3]. Knowledge production involves the creation of new knowledge, such as new ideas, innovations and insights spawned by interaction between people or groups and the acquisition of knowledge from outside sources. In knowledge validation, potential new knowledge is subjected to expert review and processes that test its reliability and value in practice. Knowledge that passes these tests is then integrated, or implemented, within the organization in the knowledge integration phase.

One of the main problems in knowledge production is the fact that knowledge is not always easily expressed explicitly by means of a formal representation language, i.e., in words and numbers and shared in the form of data, scientific expressions, specifications, manuals, etc. [3] Therefore, the role of tacit knowledge which is far to be reduced to explicit expressions and cannot be articulated (but it can be learned, acquired or managed), has to be taken into account, too. For example, in the context of ERP knowledge individual users' absorptive capacity plays a significant role in knowledge transfer from ERP consultants to members of a recipient organization [4]. Official training and education is not sufficient to have all the ERP users become sufficiently familiar with ERP systems to use them effectively. Accordingly, practices embedded in ERP packages are explicit knowledge that users must understand [5]. However, holistic knowledge involves applying expertise, and creating, sharing and distributing it [6] [7]. Expertise can be tacit. Therefore, customization is often required when the tasks and business processes of buyers are different from those of the standardized package. This is one reason why so many ERP installations fail because consultants' technical and users' tacit business knowledge sometimes collide [5].

\section{ABSORPTIVE CAPACITY}

Absorptive capacity (AC) of a firm can be studied either at the collective or individual level. The AC of an organization depends on that of its individuals; a firm's 
absorptive capacity can be determined by the aggregation of its members' capacity [8]. Ref. [5] adopted the definition of absorptive capacity as the ability of an organizational member "to value, assimilate, and apply new knowledge [8]." Ref [9] conceptualized absorptive capacity as a broad set of organization member "skills needed to deal with the tacit component of transferred knowledge and needed to modify this imported knowledge." Ref. [10], in turn, conceptualized user absorptive capacity as "a set of organizational routines and processes by which firms acquire, assimilate, transform, and exploit knowledge to produce a dynamic organizational capability." User absorptive capacity is classified into three interrelated components: a user's capacity for understanding external knowledge, a user's capacity for assimilating knowledge, and a user's ability to apply knowledge to the task [5]. The first component corresponds to "the acquisition phase in the knowledge life cycle'". Ref. [11] argues that the absorptive capacity is strongly related to the members' prior knowledge base about the object. Other authors (e.g. [12] [13] [4]) state that when organization members possess greater prior knowledge, they can absorb new knowledge more effectively.

The second component, a user's capacity for assimilating knowledge refers to a user's ability to internalize new knowledge into his or her task environment. Once organizational members understand new knowledge, they need to assimilate it. The third component is similar to "problem-solving skills" and associated with the "exploitation phase" in organization-level absorptive capacity.

\section{KNOWLEDGE EXPLOITATION}

Organizations' performances reflect different combinations of their abilities to both explore new knowledge and exploit existing knowledge [14]. Knowledge exploration was defined as the pursuit of new competencies, and knowledge exploitation as the use and further development of existing competencies [15] [16]. Ref. [17] defined exploration as learning activities that lead to the addition of new resources and exploitation as learning activities involving the use of resources the firm already has.

As to learning, the factors that are assumed to influence $\mathrm{AC}$ are discussed in the literature [18]. One of them is prior knowledge and individuals' skills. The more education and training an employee receives, the higher his or her individual ability to assimilate and use new knowledge will be [8]. As firms' ACs depend on those of their employees, the general level of education, experience and training their employees have, has a positive influence on firms' level of AC. To manage the knowledge life cycle process, different individual absorptive capacities are needed. Ref. [19] found that (small) firms need well-educated technicians, engineers and technological specialists to access knowledge from outside their boundaries. Ref. [20] takes this into account in their analysis by including the share of scientists and engineers in total employees as well as training expenditures in their model.

In the management of customer and market knowledge, we have to take into account different uses of knowledge.
One major distinction is between "instrumental" and "conceptual" uses of knowledge [21] [22]. Instrumental use refers to the direct application of knowledge to solve a particular problem or make a particular decision. The conceptual use of knowledge refers to information utilized for general enlightenment rather than for any current action a decision maker is contemplating. [23] Distinctions are also commonly made between knowledge which has a clear physical manifestation, such as a new technology being expressed as a new product or service, and knowledge which is manifested only as an idea or concept [24] [25]. We argue that all the kinds of knowledge mentioned above are present in a successful industrial service innovation and development.

The presence of the so-called 'gatekeepers' plays an important role in determining AC. Gatekeepers, whose role is to create a language which can be understood by different departments and to act as 'boundary spanner' within the firm or as an interface between the firm and its environment [8] improve a firm's AC through knowledge sharing [26].

Exploitation is basically the process of gaining competence by adopting, synthesizing, and applying current existing knowledge [27] [28]. Knowledge exploitation can be divided into internal and external knowledge exploitation. At a firm's level, external knowledge exploitation refers to the commercialization of knowledge assets, for example, by means of technology licensing. It can occur independently from a firm's product business or in addition to the application of knowledge in a firm's own products [29] [30]. External knowledge exploitation potentially allows firms to capture additional value from their knowledge [31]. In service innovation, knowledge is often simultaneously exploited both internally and externally because of the strategic motives for knowledge transfer. An external knowledge exploitation capability requires open employee attitudes, which may fundamentally affect a firm's management of knowledge transactions [32] [33] [34. However, protective attitudes concerning outward knowledge transfer seem to be embedded in many industrial companies [29]. Conditioned by the firm's organizational context, employees may attribute negative connotations to inter-firm knowledge transfer [35] [36]. Not-invented-here (NIH) tendencies [36] [30] refer to negative attitudes toward acquiring external knowledge. Ref. [37] adopted the notion of not-sold-here (NSH) tendencies. They defined NSH tendencies to be "protective attitudes toward external knowledge exploitation" (p.1055). Because of NSH attitudes, organizations may be unable to actively transfer knowledge internally or externally, even though their strategy may intend to do so.

In line with [15] [16], we define individual knowledge exploitation as the use and further development of existing firm competences in customer knowledge management by individual members of a firm. Competences addressed in the empirical part of the study are technological competences, system competences and human competences in the context of industrial service innovation and development. 


\section{Methodology}

We carried out an exploratory case in nine Finnish industrial companies referring to themselves as service companies even though six of them were traditional manufacturers offering also services. Three of the case companies were industrial service providers. In the first phase, the researchers visited pairwise all the nine companies conducting preliminary discussions with the company representatives. The discussions lasted approximately two hours and were tape recorded and transcribed. Based on the analysis of the discussions and the literature review, a semistructured interview guide was created with the themes of the services offered, customers and customer contacts, customer information and its utilization as well as service innovation and development. Thereafter, altogether 31 interviews (one group interview, 30 individual interviews) were conducted on the case companies' premises with, e.g., a general manager of service business, product manager, salestechnician, maintenance manager, business manager, global account manager, sales manager, general manager of global product management, vice president, service development engineer, product development manager, sales director, commercial director, a product director and sales people. The length of the interviews varied from two to two and half hours.

The transcribed interview data produced nearly 700 pages of text. The material was first analyzed by the ARA (actors, resources, activities) model. Then, following the recommendations [38], we conducted both within case and cross case analyses by the themes. We followed abduction logic by moving iteratively between theory and the empirical data. The method enabled interaction among existing ideas, former findings, new ideas and new observations [39].

For the purpose of this paper, all the transcribed interviews were first read by two researchers in order to form a concise picture of the acquisition, assimilation, transformation and exploitation of customer information in each organization. Thereafter, the transcriptions were re-red by focusing on the individual exploitation of customer knowledge.

\section{FINDINGS OF THE STUDY}

Despite the fact that all the companies considered themselves as service companies, the interviewees found it difficult to define what service business means in their company. For some, it was traditional maintenance and spare part services, for another, totally new business opportunities and business lines. Many of the companies were developing value-added services to widen their service offering portfolios. Common to all the companies was increased sensitivity to customer knowledge. The interviewees saw customer information and knowledge crucial for the development of services that would satisfy the customers' needs. They expressed the need to learn to listen to the customers to acquire knowledge about the changes in the customers' processes and satisfaction to be able to incrementally improve existing services and service delivery. Intra-organizational communication of customer knowledge was facilitated and improved by developing communication structures and IT systems in the case companies.

\section{A. Individual exploitation of technology in customer knowledge management}

The members of the case companies utilized different information systems to collect, store and disseminate customer knowledge. The interviewees mentioned such IT tools as maintenance information and management systems, engineering information systems, project management and invention announcement systems and ERP (Enterprise Resource Planning) systems. The exploitation of ERP systems was seen important especially in the companies responsible for the customers' production lines, e.g. in a factory automation supplier, where the personnel has to be able to quickly respond to the need for maintenance or repair service.

In five out of the nine companies employees used the existing Customer Relationship Management (CRM) application. The development of CRM was seen very important also in the companies which currently did not have such systems, and CRM systems were currently in the development phase. Employees also utilized customer databases, digital reports of maintenance and repair visits, sales tools, and technical information bases on the Intranet as well as digital team tools.

The exploitation of the IT systems varied in the companies. The interviewees identified several challenges regarding the use of IT systems. The most often mentioned obstacle to external customer knowledge exploitation, especially knowledge sharing was the lack or the inadequacy of IT systems. This was evident, for example, in a company where several IT systems were in use in different units around the world and there were difficulties in systems integration, although the need to make these systems communicate with each other was apparent. In another company, customer knowledge was also scattered in multiple IT systems. Thus, it was tiresome and time consuming to find the appropriate information in the system, because of the vast amount of non-structured information. The interviewees longed for some kind of a search machine like Google to facilitate the information search.

The question raised by the interviewees was how to make sure that people start exploiting IT systems such as CRM. The culture of activity, especially in the smallest organization relied on a non-structured information storage and personal interaction in knowledge transfer. As the organization remained small and people had long working careers in the same organization, important knowledge was dispersed through the organization sufficiently. However, incorporating more services into the firm's offering, internationalization and an increased need for efficiency meant that the amount of customer knowledge which should be exploited grew exponentially and there was the need to store customer knowledge in one place.

The representatives of each company pointed out that though effective IT systems are almost necessary, they are in the end - merely assisting tools. Further development of 
technology competences and IT tools calls for the examination of goals, communication structures and cooperation inside and outside the organization and between different organizational units. For example, the representatives of one company pointed out that there were several internal stakeholders (e.g. sales and service provision units in addition to the interviewees responsible for customer management) who had active roles and interest in developing and providing maintenance solutions that comprises of several different services. As long as those responsible for providing different services only aim to attain their own goals without a holistic view of the customer and the understanding of the importance of internal co-operation, no technology can solve the problems regarding customer knowledge acquisition, communication and utilization.

\section{B. Individual exploitation of knowledge systems in customer knowledge management}

By knowledge systems we here refer to organizational structures, internal boundaries, communication structures, co-operation between different functions and units, culture, and strategy deployment and communication. The organizational structures of the case companies had been revised and, if necessary, reconfigured to support service development and, especially, customer knowledge exploitation in service development. The interviewees saw the exploitation of customer feedback especially crucial for the successful service delivery and the maintaining and improving of customer satisfaction.

Ongoing organizational changes were seen to slow down customer knowledge exploitation of employees by slowing down the communication in the service development because of changing individuals. In one company, several changes in the organizational structure have taken place in the recent years. As the interviewees pointed out, the flow of information breaks down when people become parts of new organizations or otherwise move into new positions. They are not familiar with new communication structures, either formal or informal, and they have to rebuild their internal and external networks. Furthermore, the lack of the knowledge about the value of the knowledge at hand to new coworkers slows down the external knowledge exploitation.

To develop communication structures in a factory automation supplier that was divided into two business areas some years ago, numerous internal trainings and marketing activities took place in order to ensure knowledge flows and customer knowledge exploitation in both the service and the product development. Furthermore, it was important to communicate the change in strategy, i.e., incorporating more services into the company's offering, to everyone in the organization. Even though the company has traditionally been project-oriented and the personnel were already used to work closely with the customers, there was still a need to improve existing communication structures.

In all of case companies, the importance of customer feedback in service development was recognized. Also the vast amount of customer knowledge owned by the customer contact personnel was known in the companies. However, the information received by frontline customer service and maintenance personnel did not reach service developers and management sufficiently. Due to the insufficient customer feedback communication (collection, storage and dissemination) systems, frontline personnel acted as knowledge gatekeepers.

The interviewees argued that people working in the customer interface were not always aware of the importance and value of the tacit customer knowledge they possessed and the feedback they received. This implies that knowledge management strategies were not properly deployed in all the organizations. The interviewees pointed out, that in order to ensure effective customer knowledge acquisition, dissemination and usage everyone in the organization has to understand it's importance and value.

As to the organizational culture, the old way of thinking and operating was still evident, for example, in an industrial wholesale and service company. The company has earlier been team and product oriented. Therefore, people representing and selling different products did not know what the other teams sold. That is why they have been, until know, unable to identify customers who might need products or services represented by the other teams than that of their own. In the new situation, the need to learn a new culture is evident. The need for facilitating communication and cooperation inside the organization was recognized and a new matrix organization was developed. In the new organization structure a customer will be able to interact with a customer account manager responsible for the whole offering of the supplier.

Service development in the case companies was often an ad hoc activity and services were tailored to the customers case by case. The lack of clearly defined service development processes made co-operation in service development projects challenging. Several interviewees pointed out that when customer knowledge reaches service developers it has already passed through several persons in the organization, because most service developers do not interact directly with customers. As the representative of one company pointed out, there were no unanimous guidelines inside the organization how to assess new ideas or how to collect customer feedback, how to analyze it and how to value it. Although customer focus groups were used in the organization, the knowledge received by service developers about customers was usually already filtered when it reached them, because it came from the sales personnel. This is why the interviewees also found that the roles in service development and provision were unclear; for example, the role of the sales organization.

\section{Individual competences in customer knowledge management}

Individual competences consist of both explicit and tacit knowledge one possesses. The amount of cumulative and tacit knowledge was huge in each of the case companies. The companies had been able to exploit tacit knowledge in the past because of the long careers and limited turnover of the employees. According to the interviewees, the risk of losing tacit knowledge when people change their position or leave the company was recognized the case companies but 
the respondents were unaware whether something was already done to facilitate tacit knowledge transfer and storage. Due to the inadequate documentation, to find knowledge about earlier development projects required knowing the right person, because information was often stored only in personal files and individual memories.

Personal networks and social competences were found important by the respondents. Even though IT systems were seen as important tools in customer knowledge management and systems were developed in each organization, the emphasis was still on social interaction mechanisms; meetings and knowledge in face-to-face situations. Therefore, the interviewees considered it important to know what other people do in order to know what knowledge to share with them because customer knowledge was to a great extent shared personally and by using e-mail.

All in all the interviewees thought that exploiting customer knowledge was extremely important. They wanted to make sure that knowledge is widely available. However, there was also a differing experience. The representatives of one company found that the culture of withholding information had traditionally been embedded in the organization because knowledge was seen as power. The interviewees saw that in order to break this tradition the openness towards knowledge sharing has to start from the top management.

Although the interviewees saw IT systems as important tools for storing and sharing customer knowledge, there was also criticism towards using these systems. One could not always be certain whether the information was up-to-date, and the depth of information varied depending on who had entered the information into the computer. One of the reasons not to exploit IT systems as much as possible was hurry. The amount of knowledge in IT systems was found staggering. It was found very time-consuming to scan for important knowledge. Scanning for information was especially difficult in companies where customer knowledge was stored in several different IT systems. Multiple IT systems made it also difficult to feed information into the computer because one had to know which application to use. The interviewees had also recognized general resistance towards exploiting IT systems. According to them, the best way to encourage people to exploit, for example, a CRM application was by informing the personnel of its benefits. Individuals have to recognize the benefit of changing their working habits.

According to the key account manager in the environmental management and services -company, it is a huge but important task to educate people to understand the importance and value of their own expertise, competences and work in the service provision. It is equally important to point out the financial and other benefits of service development and close cooperation with a customer. The interviewees believed that he shared mindset of customer orientation can be reached through discussions and education. This process was going on in the case companies.

\section{DISCUSSION AND CONCLUSIONS}

Ref. [3] divided a knowledge life cycle process into three sequential steps: knowledge production, knowledge validation, and knowledge integration. Knowledge production in service development requires interaction between people or groups and the acquisition of knowledge from outside sources. In the case companies, customer and market information exploited in service development was seldom first-hand knowledge but filtered through customer contact personnel, i.e., gatekeepers of customer knowledge. Furthermore, service developers' technical and sales personnel's business knowledge and languages used sometimes collide. That makes interaction sometimes difficult. It is important to develop communication in service development by inviting more customers and front line customer contact personnel (not only salespeople) to service development teams and thus receive first-hand customer knowledge.

The interviewees also pointed out the difficulty to recognize the value of external knowledge, which is one component of AC [40]. This component parallels knowledge validation [3]. Due to different educational backgrounds, work positions, mindsets etc. individuals evaluate and valuate different kinds of knowledge. The not-sold-here (NSH) tendency [37] was also identified in this study. If knowledge is valued as power, organizations and individuals may be unable to actively transfer knowledge internally or externally.

Knowledge integration within the organization seemed to be most challenging in the case companies. Managing knowledge is especially challenging in organizations which function globally [41]. Utilizing global IT systems enables employees to get information from different geographical areas. However, global systems can also be problematic, because exploiting them requires new skills, and making changes to improve their usability and functionality requires authorization. Developing inadequate IT requires much consideration on which applications to adopt, and who should have access to them to ensure that important customer knowledge is available for all those who need it. IT systems should also be user-friendly. Furthermore, both technical and attitudinal education is needed to get people to better exploit the potential of IT applications. Still, there has to be a shared understanding inside the organization about the importance and potential of customer knowledge acquisition, storage, sharing and usage in successful service development and provision.

Customer knowledge exploitation capability requires open employee attitudes, which may fundamentally affect a firm's management of knowledge transactions [32] [33] [34]. The top management has to clearly communicate changes in the strategy to the members of the organization. They have to share information actively and put special effort on facilitating cross-functional and cross-business area communication. The management has to encourage people to manage the new situation and to further develop processes. They also have to develop reward systems to support the 
personnel to be more customer-oriented and focus on customer knowledge acquisition, sharing and utilization.

We recognized multiple challenges concerning customer knowledge management in industrial service innovation and development; technological, organizational and human. Further research on these issues would help us to understand how to win those challenges.

\section{REFERENCES}

[1] F.E. Webster Jr., "Is Industrial Marketing Coming of Age?" in Review of Marketing 1978, T. V. Bonoma and G. Zaltman, Eds. Chicago: American Marketing Association, 1978, pp. 138-59.

[2] M. du Plessis "The role of knowledge management in innovation," Journal of Knowledge Management, vol.11 (4), 2007, pp 22-29.

[3] M.W. McElroy, The new knowledge management: complexity, learning and sustainable innovation, Elsevier; 2003.

[4] D.-G. Ko, L.J. Kirsch and W.R. King, “ Antecedents of knowledge transfer from consultants to clients in enterprise system i mplementations," MIS Quarterly, vol. 29 (1), 2005, pp. 59-85.

[5] J.-H. Park, H.-J. Suh and H.-D. Yang "Perceived absorptive capacity of individual users in performance of Enterprise Resource Planning (ERP) usage: The case for Korean firms", Information \& Management, vol. 44, 2007, pp. 300-312.

[6] M. Alavi and D.E. Leidner " Review: knowledge management and knowledge management systems: conceptual foundations and research issues," MIS Quarterly, vol. 25 (1), 200, pp. 107-136.

[7] M.C. Boudreau and D. Robey "Enacting integrated information technology: a human agency perspective," Organization Science, vol. 16 (1), 2005, pp. 3-18.

[8] W.M. Cohen and D.A. Levinthal, "Absorptive Capacity: A New Perspective on Learning and Innovation," Administrative Science Quarterly, vol. 35, 1990, pp. 128-152.

[9] D.C. Mowery and J.E. Oxley "Inward technology transfer and competitiveness: the role of national innovation systems," Cambridge Journal of Economics, vol. 19, 1995, pp. 67-93.

[10] S.A. Zahra and G. George "Absorptive capacity: a review, reconceptualization, and extension," Academy of Management Review, vol. 27 (2), 2002, pp. 185-203.

[11] L. Kim "Crisis construction and organizational learning: capability building in catching up at Hyundai Motors,".Organization Science, vol. 9, 1998, pp. 506-521.

[12] G. Szulanski "Exploring internal stickiness: impediments to the transfer of best practice within the firm," Strategic Management Journal, vol. 17, 1996, pp. 27-43.

[13] C. O'Dell and C.J. Crayson "If only we knew what we knowidentification and transfer of internal best practice," California Management Review, vol. 40 (3), 1998, pp. 154-174

[14] D.A. Levinthal and J.G. March "The myopia of learning," Strategic Management Journal, vol. 14, 1993, pp. 95-112.

[15] J.G. March "Exploration and exploitation in organizational learning," Organization Science, vol. 2, 1991, pp. 71-87.

[16] I. Marengo "Knowledge distribution and coordination in organization: on some social aspects of the exploitation vs. exploration trade-off," Revué Internationale de Systémique, vol 7, 1993, pp. 553571.

[17] S.B. Sitkin, K.M. Sutcliffe and R.G. Schroeder "Distinguishing control from learning in total quality management - A contingency perspective,".Academy of Management Review, vol. 19, 1994, pp. 537-564.

[18] T. Schmidt "Absorptive Capacity - One Size Fits All? A Firm-level Analysis of Absorptive Capacity for Different Kinds of Knowledge," Managerial and Decision Economics, vol. 31, 2010, pp. 1-18.

[19] R. Rothwell and M. Dodgson "External linkages and innovation in small and medium-sized enterprises," R\&D Management, vol 2, 1991, pp. 125-137.
[20] M. Frenz, J. Michie and C. Oughton, Co-operation, innovation and firm's absorptive capacity, mimeo, 2004.

[21] N. Caplan, A. Morrison and R.J. Stambaugh, The Use of Social Science Knowledge in Public Policy Decisions at the National Level. Ann Arbor, MI: Institute for Social Research, 1975

[22] R.F. Rich, The Power of Social Science Information and Public Policy Making. San Francisco: Jossey-Bass, 1979.

[23] R. Deshpande and G. Zaltman "Factors Affecting the Use of Market Research Information: A Path Analysis," Journal of Marketing Research, vol. 19 (1), 1982, pp. 14-31.

[24] J.K. Larsen "Knowledge Utilization: What Is It," Knowledge: Creation, Diffusion, Utilization, vol. 1(3), 1980, pp. 421-442.

[25] G. Zaltman "Knowledge Utilization as Planned Social Change," Knowledge: Creation, Diffusion, Utilization, vol. 1 (September), 1979, pp. 82-105.

[26] A.L. Vinding, Absorptive Capacity and Innovation Performance: A Human Capital Approach. Department of Business StudiesRUID/IKE Group, Denmark: Aalborg University, 2000.

[27] M.A. Lyles and C.R. Schwenk "Top management, strategy and organizational knowledge structures," Journal of Management Studies, vol. 29, 1992, pp. 155-174.

[28] W. Liu "Knowledge Exploitation, Knowledge Exploration, and Competency Trap," Knowledge and Process Management, vol. 13 ( 3), 2006, pp. $144-161$.

[29] D. Kline "Sharing the corporate crown jewels," MIT Sloan Management Review., vol. 44 (3), 2003, pp. 89-93.

[30] U. Lichtenthaler and H. Ernst "Attitudes to externally organising knowledge management tasks: A review, reconsideration and extension of the NIH syndrome," R\&D Management, vol. 36 (4), 2006, pp. 367-386.

[31] D.J. Teece "Capturing value from knowledge assets: The new economy, markets for know-how, and intangible assets," California Management Review, vol. 40 (3), 1998, pp. 55-79.

[32] D.J. Teece, G. Pisano and A. Shuen "Dynamic capabilities and strategic management," Strategic Management Journal, vol. 18 (7), 1997, pp. 509-533.

[33] H. Chesbrough, Open Innovation: The New Imperative for Creating and Profiting from Technology. Boston: Harvard Business School Press, 2003.

[34] C.E. Helfat, S. Finkelstein, W. Mitchell, M.A. Peteraf, M.A., M. Singh, D.J. Teece and S.G: Winter, Dynamic Capabilities: Understanding Strategic Change in Organizations. Oxford, UK: Blackwell Publishing, 2007.

[35] H.H. Kelley and J.L. Michela "Attribution theory and research," Annual Rev. Psych., vol. 31, 1980, pp. 457-501.

[36] R. Katz and T.J. Allen "Investigating the not-invented-here (NIH) syndrome: A look at the performance, tenure, and communication patterns of $50 \mathrm{R} \& \mathrm{D} \quad$ project groups," R\&D Management, vol. 12 (1), 1982, pp. 7-19.

[37] U. Lichtenthaler, E. Holger and M. Hoegl, "Not-Sold-Here: How Attitudes Influence External Knowledge Exploitation," Organization Science, vol. 21(5), 2010, pp. 1054-1071.

[38] K.M. Eisenhardt "Building Theory from Case Study Research," Academy of Management Review, vol. 14(4), 1989, pp. 532-550.

[39] A. Coffey and P. Atkinson, Making Sense of Qualitative Data: complementary research strategies. Thousand Oaks, California: Sage, 1996.

[40] F. van den Bosch, R van Wijk R. and H. Volberda "Absorptive capacity: Antecedents, Models and Outcomes," in The Blackwell Handbook of Organizational Learning and Knowledge management, M. Easterby-Smith, and M.Lyles, Eds. Oxford: Blackwell, 2003, pp. 278-302.

[41] D. Moitra and K. Kumar "Managed Socialization: How Smart Companies Leverage Global Knowledge, "Knowledge and Process Management, vol. 14 (13), 2007, pp. 148-157. 